\title{
Stay or switch? Investigating lock-in effect in multi-channel apparel retailing
}

\author{
Emiliano Acquila-Natale* • Ángel Hernández-García \\ Santiago Iglesias-Pradas • Julián Chaparro-Peláez
}

Universidad Politécnica de Madrid, Madrid, Spain

Received: 12 December 2019

Revised: 24 March 2020

Accepted: 30 April 2020

\begin{abstract}
The emergence of new sales channels, the irruption of new technologies and changes in personal and professional lifestyles have transformed purchasing behaviors throughout the shopping process. Prior research has addressed the effect of these changes in each channel separately, neglecting the study of such effects in multi-channel environments. This research investigates the relation between channel preference and spillover effect-and more particularly, lock-in effect-in apparel multi-channel retailing, with data collected from a survey of 432 Spanish shoppers. The results of the study facilitate further understanding of spillover effect and help companies improve their omnichannel strategies.
\end{abstract}

Keywords: multi-channel; spillover effect; lock-in effect; channel integration; retail JEL Classification Codes: M31, D12, L81

\section{Introduction}

The evolution of retail toward channel integration has impacted the way consumers shop and behave, and vice versa, affecting all the stages of the shopping process. In each stage, consumers make an evaluation of the pros and cons of every available channel, selecting the option that better suits their needs (Kemperman et al., 2015). In a general sense, a consumer's shopping decision process spreads through the following stages (Levy et al., 2012): prepurchase, including need recognition and information search; purchase, or the moment the consumer pays for the product; and post-purchase, which refers to consumption of the product and evaluation of the purchase after sale.

Because traditional models of the shopping process generally do not consider activities such as delivery, pick-up, returns/exchanges or customer support as part of the post-purchase stage, there is an increasing interest in these activities in multi-channel retailing. The emergence of

\footnotetext{
*Corresponding author. E-mail: emiliano.acquila@upm.es.
}

Citation: Acquila-Natale, E., Hernández-García, Á., Iglesias-Pradas, S., and Chaparro-Peláez, J. (2020) Stay or switch? Investigating lock-in effect in multi-channel apparel retailing, Economics and Business Letters, 9(4), 298305.

DOI: $10.17811 /$ ebl.9.4.2020.298-305 
online retailing has seamlessly incorporated these services as part of the shopping experience (Lantz and Hjort, 2013) due to the impossibility of evaluating a product at the time of purchase, which can become one of the most important barriers for online purchasing of physical products (Liao et al., 2010). Further, channel integration usually involves higher variety of options for delivery, pick-up, returns and exchanges of products to give consumers more freedom (Kemperman et al., 2015). Consequently, consumers may now make different shopping decisions at any given moment, choosing different channels for information search, product selection, payment and reception of the product (Verhoef et al., 2015). This change has a profound effect on the way companies run their business and which new shopping options they provide, sometimes without a clear idea about how to implement them or without reliable information about how to measure the benefits of such implementation. These new shopping options include, but are not limited to, showrooming - in-store product trial followed by online purchase, especially relevant in touch and feel products-, webrooming - online information search and in-store purchase - or click-and-collect, where customers may purchase the product online and pick it up in the physical store, allowing for immediate return of items.

The increasing range of available shopping options and channels leads to the concept of channel preference. A consumer shows preference for a given channel when the number of activities carried out using that channel, for each stage of the shopping process, is higher than the number of activities carried out using any other channel. For example, a consumer shows a channel preference during the purchase stage when the number of paid purchases using that channel is higher than the number of payments in other channels. Further, some consumers may share the same channel preference, but at different levels of intensity; for instance, consumers who buy their products using exclusively one channel would show higher intensity of channel preference than consumers who mainly purchase using that channel, but also use some other channel for their purchases (Acquila-Natale and Iglesias-Pradas, 2020). The concept of spillover effect (Gensler et al., 2012) is tightly related to the stability of channel preference along the different stages of the shopping process; spillover effect involves the use of the same channel in subsequent stages of the shopping process (lock-in), or of two or more channels (cross-channel synergy) in the same or different stages (Verhoef et al., 2007).

Prior studies confirm a relation between lock-in effect and consumer behavior in different sectors; lock-in is more likely to occur in physical or offline contexts, especially in the case of products with high sensorial content (Verhoef et al., 2007; Zhai et al., 2017); conversely, crosschannel behaviors are more likely to happen in online environments, where online information search does not always translate to online purchasing (Verhoef et al., 2007; Zhai et al., 2017), which is why we posit "Hla. From a sequential view, lock-in effects are less likely to occur for online than offline information search purposes." and "H1b. When purchasing channel preference is accounted for, lock-in effects between information search and purchase are more likely to occur in online than offline channels" to reflect both the sequential and purchasing channel preference views of lock-in effects. Further, strong preference for offline shops encourages offline searching (Kim et al., 2019) and online buyers more often rely on online information channels than offline buyers (Voorveld et al., 2016), which is why we posit " $H 2$. Lock-in effects will be more pronounced among consumers with higher intensity of channel preference."

Channel switching in online contexts may be low between pre-purchase and purchase because consumers try to lower transaction costs and improve their efficiency by using a single channel (Bhatnagar and Papatla, 2016; Gensler et al., 2012); however, when shoppers search and purchase online most of them tend to go to the store for after-sales service (De Keyser et al., 2015; Frasquet et al., 2015). Therefore, we posit "H3. The presence of lock-in effect is lower when activities involving product returns and exchanges (H3a) and customer service and support $(\mathrm{H} 3 \mathrm{~b})$ are included, regardless of purchasing channel preference." 


\section{Methods and materials}

Because consumer behavior changes depending on the product under study (Frasquet et al., 2015), this research focuses on clothing and apparel for two reasons: the particular characteristics of this type of product, of a sensorial, look and feel nature, and the increasing number of sales of clothing and apparel in online channels (Urueña et al., 2018). To test the research hypotheses, an online questionnaire was delivered to a sample of 842 Spanish clothing and apparel shoppers, of which 432 valid responses were returned (51.3 percent response rate). Validation of responses included observing that the questionnaire was responded in its entirety and that the responses did not show response set behaviors or inconsistencies across items. In order to ensure representativeness of the sample, the questionnaire was delivered to different groups: university students and faculty, a database of Spanish city councils, contacts in social networking sites and homes for the elderly. Respondents were encouraged to further forward the questionnaire to relatives and friends by participating in a raffle of a 25-euro card redeemable in a clothing store of their choice. The demographics of the sample were then contrasted with official reports of the Spanish population, internet users and clothing and apparel shoppers (INE, 2018; Modaes.es, 2018; Urueña et al., 2018).

The questionnaire included questions for demographic segmentation, followed by questions to determine channel preference from Montoya-Weiss et al. (2003) and Frambach et al. (2007), adapting the scale to the characteristics and options available in each stage of the shopping process. Thus, respondents were asked to indicate which of the different channels they had used preferentially during the last year to perform the following activities: information search, purchasing, product reception or pick-up, returns and exchanges, and customer service or support. Additionally, they were asked to indicate the percentage of use of each of the different channels to characterize intensity of purchasing channel preference.

For the purpose of this study, lock-in is inferred from channel preference statements of respondents across the different stages of the shopping process. The study proposes a dual view of lock-in effects, including the study of sequential channel lock-in effects along the stages of the shopping process and lock-in effects based on purchasing channel preference; that is, when an individual expresses preference for the same channel in previous or subsequent stages, the analysis considers that lock-in effect exists. It is worth noting that all respondents have used some channel for information search, purchase and delivery/pick-up purposes, but some of them have not used returns and exchanges (10 percent of the sample) or customer support services (20 percent of the sample). These responses have been excluded from the analysis of lock-in effect in those stages.

$\mathrm{H} 1 \mathrm{a}$ and H1b have been tested using an independent t-test between consumers with preference for online shopping - including three different channels: web, mobile and social networksand those with preference for offline shopping. Testing $\mathrm{H} 2$ involves observation of the value and significance of bivariate correlations between the existence of lock-in effect and intensity of channel preference for the global sample and in each of the two subgroups. Finally, to test $\mathrm{H} 3$ the research uses a paired-samples t-test to analyze lock-in effect considering the stages of pre-purchase, purchase and delivery/pick-up, on the one hand, and possible changes when including exchanges and returns, and/or customer service, on the other hand.

\section{Results}

The analysis covers the global sample and both subgroups and considers three scenarios (Fig. 1): (Sc1) inclusion of prepurchase, purchase and delivery/pick-up only; (Sc2) inclusion of returns and exchanges; (Sc3) inclusion of customer service. Tables 1 and 2 show the frequency distribution of channel preferences and the different spillover effects, respectively, and Fig. 2 displays the percentage of shoppers where lock-in effect has been determined considering only 
purchasing channel preference. Fig. 1 evidences the existence of research online and purchase offline behaviors and also that online shoppers do not tend to search information offline. From Table 2 and Fig. 2, it is possible to observe that spillover effects seem to be stable in the offline channel throughout the shopping process when considering purchasing channel preference, whereas the effect varies in the online channel depending on the number of stages under consideration. Lock-in effects seem to decrease dramatically in Sc2 and Sc3 in digital channels.

The independent-samples t-test of the differences shown in Figure 1 and Figure 2 returns a negative and statistically significant $(p<0.001)$ difference between offline and online channel preference in Sc1, but positive and statistically significant difference in Sc2 and Sc3. The results of the analysis support H1a and H1b, and suggest that for simplified shopping scenarios-i.e. limited to information search, purchase and product delivery/pick-up - the presence of lock-in effect is more pronounced in digital channels than in offline channels when considering only purchasing preference and more pronounced for offline shoppers when considering the sequential stages of the purchasing process. Lock-in in the offline channel is more stable than in the digital channel when including additional post-purchase activities.

Figure 1. Graphic summary of the models (continuous lines indicate lock-in effect). The analysis includes a dual view: traditional channel lock-in effects (in blue) and lock-in effects based on purchasing channel preference (in yellow).

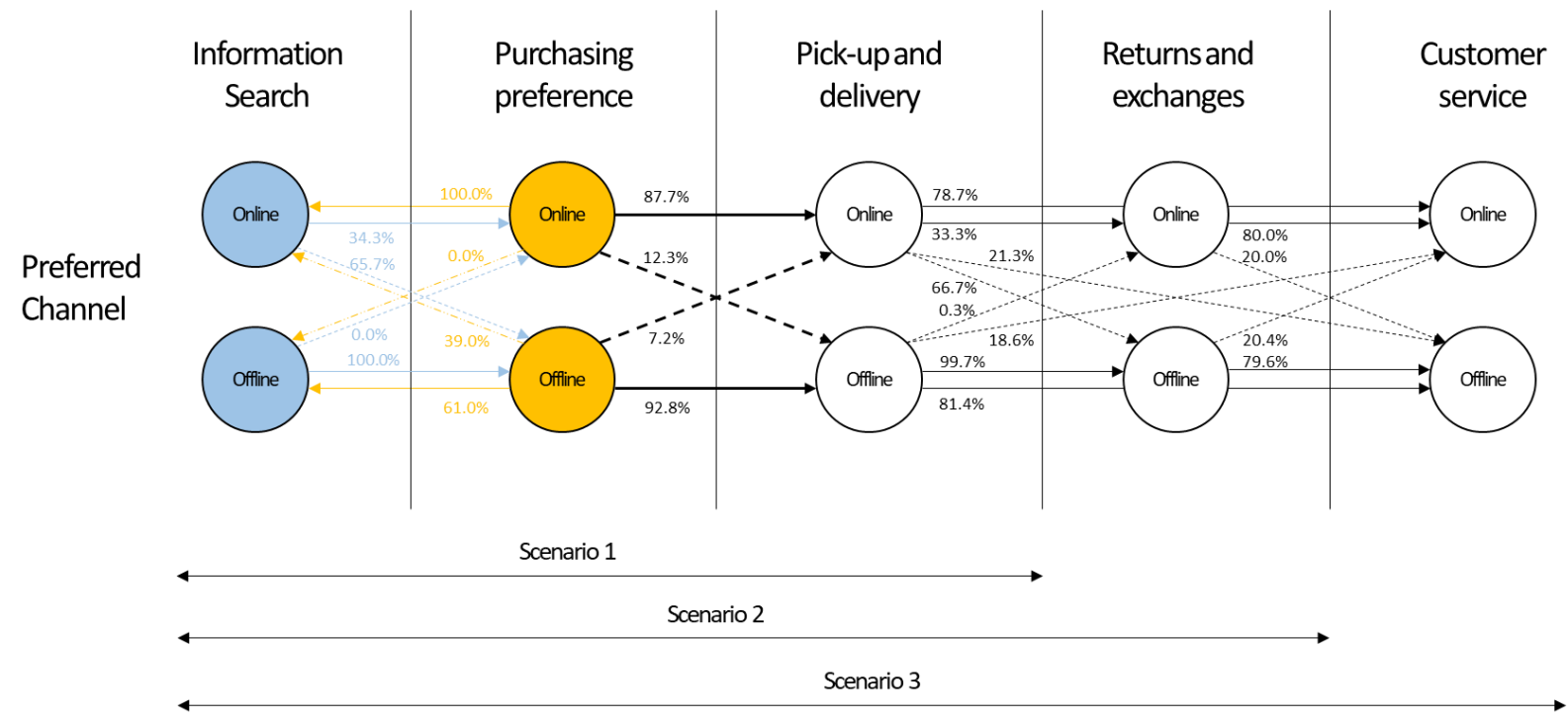

Figure 2. Channel lock-in effects and lock-in (based on purchasing channel preference).

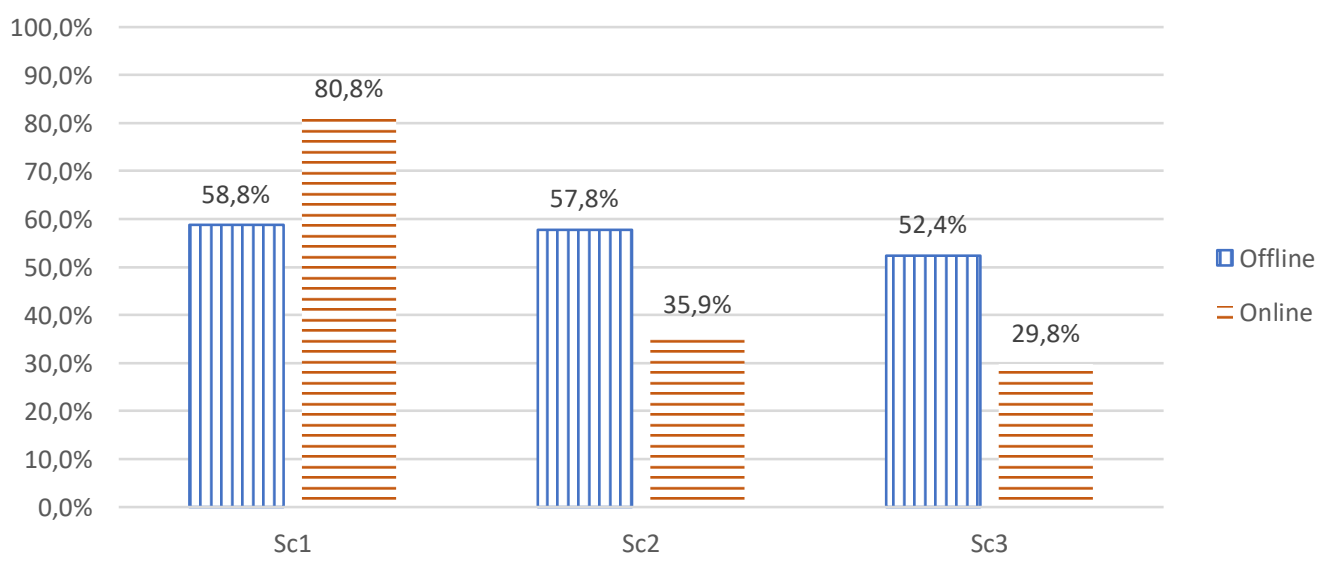


Table 1. Frequency of declared channel preference across the stages of the shopping process.

\begin{tabular}{lrrrrr}
\hline $\begin{array}{l}\text { Declared } \\
\text { channel } \\
\text { preference }\end{array}$ & Search & Purchase & $\begin{array}{r}\text { Pick-up and } \\
\text { /delivery }\end{array}$ & $\begin{array}{r}\text { Returns and } \\
\text { exchanges }\end{array}$ & $\begin{array}{r}\text { Customer } \\
\text { service }\end{array}$ \\
Offline & 219 & 359 & 342 & 363 & 233 \\
Online & 213 & 73 & 90 & 27 & 97 \\
\hline \hline
\end{tabular}

Table 2. Frequency of spillover effects based on purchasing channel preference in the three research scenarios.

\begin{tabular}{|c|c|c|c|c|c|c|c|c|c|}
\hline \multirow{2}{*}{$\begin{array}{l}\text { Preferred } \\
\text { purchasing } \\
\text { channel }\end{array}$} & \multicolumn{3}{|c|}{$\overline{~ S c 1}$} & \multicolumn{3}{|c|}{ Sc2 } & \multicolumn{3}{|c|}{ Sc3 } \\
\hline & (1) & (2) & (T) & (1) & (2) & $(\mathrm{T})$ & (1) & (2) & (T) \\
\hline Offline & 211 & 148 & 359 & 189 & 137 & 326 & 143 & 130 & 273 \\
\hline Online & 59 & 14 & 73 & 23 & 41 & 64 & 17 & 40 & 57 \\
\hline
\end{tabular}

Notes: (1) Lock-in. (2) Cross-channel. (T) Total.

Pearson's correlation between intensity of channel preference and lock-in in the total sample is $0.26(\mathrm{p}<0.05)$ in $\mathrm{Sc} 1$, but it rises to 0.42 and 0.41 (both at $\mathrm{p}<0.05$ ) in $\mathrm{Sc} 2$ and $\mathrm{Sc} 3$, respectively. The results then seem to support $\mathrm{H} 2$, showing a moderate but statistically significant relationship between lock-in effect and intensity of channel preference that becomes more important as more stages are included. Because observation of the global sample may offer a biased view of the phenomenon, the correlation analysis has also been conducted for both groups separately. The results show that the relationship between presence of lock-in effect and intensity of channel preference is moderate to high, and statistically significant for offline shoppers ( $\mathrm{Sc} 1, r=0.42 ; \mathrm{Sc} 2, r=0.43 ; \mathrm{Sc} 3, r=0.45 ; \mathrm{p}<0.05)$ whereas the relationship is not significant ( $\mathrm{Sc} 1, r=0.18 ; \mathrm{Sc} 2, r=0.20 ; \mathrm{Sc} 3, r=-0.08 ; \mathrm{p}>0.05$ ) for online shoppers. The cause of these results may lie in the presence of a large group of 'pure offline shoppers' in the sample, who only use the offline channel for all the activities of the shopping process.

Finally the paired-samples t-test returns a non-significant difference in the offline channel (diff. $=0.00 ; p=0.32)$ and a significant difference in the online channel (diff. $=0.44 ; p=0.00)$ when comparing Sc1 and Sc2, and significant differences (offline, diff. $=0.05, \mathrm{p}=0.00$; online, diff. $=0.51, \mathrm{p}=0.00$ ) when comparing Sc1 and Sc3 and also (offline, diff. $=0.04, \mathrm{p}=0.00$; online, diff. $=0.09, \mathrm{p}=0.02$ ) when comparing Sc2 and Sc3. The results seem to support $\mathrm{H} 3 \mathrm{a}$ and $\mathrm{H} 3 \mathrm{~b}$ in the online channel and only partially in the offline channel, revealing lower presence of lockin effect when including post-purchase activities, especially when customer support is involved; when this situation happens, a significant number of consumers seem to adopt cross-channel behaviors, be it using the offline channel for returns and exchanges, or contacting with the vendor or brand via telephone or using social networks for customer service and support.

\section{Discussion and conclusions}

This study provides a better understanding of channel preference as part of the shopping decision process, measuring spillover effect, and more particularly analyzing lock-in effect, in a sample of Spanish shoppers of clothing and apparel. The results show that 52.4 percent of shoppers with preference for offline purchasing use physical channels throughout all the activities of the shopping process, compared to 29.8 percent of online shoppers. The results confirm that strong preference for offline shops encourages offline searching (Kim et al., 2019). The analysis also confirms the relatively low lock-in power of the online channel (Verhoef et al., 2007; Zhai et al., 2017) and unveils two different types of online shoppers based on their behaviors: those who tend to do research online and purchase offline and those who seem to value the convenience associated with online shopping, provided that they find no issues in the 
post-purchase process. The latter suggests that when "everything goes as expected", online shoppers follow a single-channel use behavior, turning to use other channels when they encounter problems. These shoppers tend to solve their problems using the offline channel for returns and exchanges, or to contact customer support services by telephone or going to the store, which is consistent with Miquel-Romero et al.'s (2020) finding that omnichannel retail shoppers choose to complain at the store, despite having other online channels available. This finding suggests that pure players should establish physical touchpoints to give a better response to customers' returns, exchanges and complaints.

The study also confirms the reduction of lock-in effect as the shopping process incorporates more activities, in line with Bhatnagar and Papatla (2016) and Gensler et al. (2012); this reduction is more abrupt in the case of online shoppers. An important finding of this study is that the number of single-channel users in the offline channel remains stable, indicating high loyalty of consumers to the offline channel, but multi-channel behaviors increase in the online channel, with a decrease of 40 percentual points when post-purchase activities are included.

There are three bottom lines of this study. First, the results confirm the paradox that "offline retailing is dead and dying, yet it is also alive and thriving" (Alexander and Cano, 2019; p. 59); in other words, retailers not attending both the online and offline channels are at peril. For traditional retailers, online to offline commerce is imperative, which requires creating engaging physical experiences in store and the integration of online and offline information (Alexander and Cano, 2019; Yang et al., 2020) to encourage loyalty behaviors among customers - especially considering that consumers who are highly capable of employing different channels also have higher intentions to switch between retailers (Chiu et al., 2011). Second, the focus on physical shopping experiences is highly important because of the value of customers sticking to only one channel, who tend to be not only loyal to the channel but also to the brand (Kim et al., 2019). Third, physical touchpoints are essential for pure players; where offline-first retailers shift from fulfillment into experience-focused centers to benefit from webrooming and crosschannel behaviors, online retailers should start their transition towards showrooming, click and collect and zero-inventory stores to "supercharge" customer value (Bell et al., 2018) and decrease free-riding behaviors (Chiu et al., 2011).

The study is not exempt from limitations; the sample used in this research is representative of the Spanish population, but it does not provide a fine-grained view of the different customer segments. For example, covariates such as age might have an impact, not so much on the overall results -which are in line with previous studies- but rather in the distribution of frequencies, as younger consumers -e.g. Millennials- show a more balanced distribution of pure offline, research online/purchase offline and research online/purchase online behaviors (Słowikowska, 2019); we concede that the results could differ with other product categories and further validation is needed across different retailing sectors. We also acknowledge the difficulty in generalizing the results of this study to developing countries but, given that Spanish clothing and apparel shoppers show similar behaviors in multichannel and omnichannel behaviors as those of consumers in other countries -e.g. Buldeo Rai et al. (2019)-, we believe that the findings from this study could be extrapolated to other Western and Southern European countries, even though further confirmation of the results of this analysis is required. Generalization of results to countries with higher adoption of online shopping, such as United Kingdom or Northern European countries (Eurostat, 2020), would also help confirm the results of this research, or put them into a wider context.

A final limitation of the study is the low number of mobile and social network shoppers. Eighty percent of respondents have made purchases using their mobile devices, but only 2.5 percent of them declare their preference for purchases through this channel. Use and preference for social network purchases (18.8 percent and none, respectively) are even lower. Two complementary views may explain this result: from the supply side, only 36 percent of clothing 
and apparel vendors have a mobile app to access their shop (Acquila-Natale and ChaparroPeláez, 2020) and the use of social shopping is still marginal and seen more as support to other sales channels than a sales channel on its own (Elogia, 2018); from the demand side, the aging of Spanish population, with more than 30 percent of the total population over 55 years old (INE, 2018), might be hindering the adoption of newer sales channels.

\section{References}

Acquila-Natale, E. and Chaparro-Peláez, J. (2020) The long road to omnichannel retailing: an assessment of channel integration levels across fashion and apparel retailers, European Journal of International Management, 14(6), 999-1023. https://doi.org/10.1504/EJIM.2020.110562

Acquila-Natale, E. and Iglesias-Pradas, S. (2020) How to measure quality in multi-channel retailing and not die trying. Journal of Business Research, 109, 38-48. https://doi.org/10.1016/j.jbusres.2019.10.041

Alexander, B. and Cano, M. B. (2019) Futurising the physical store in the omnichannel retail environment. In Piotrowicz, W. and Cuthbertson, R. (Eds.): Exploring Omnichannel Retailing. Springer: Cham., 197-223.

Bell, D. R., Gallino, S. and Moreno, A. (2018) The Store Is Dead — Long Live the Store. MIT Sloan Management of Review, 59(3), 59-66.

Bhatnagar, A. and Papatla, P. (2016) Increasing online sales by facilitating spillover shopping, Journal of Retailing and Consumer Services, 29, 58-69. https://doi.org/10.1016/j.jretconser.2015.11.009

Buldeo Rai, H., Mommens, K., Verlinde, S. and Macharis, C. (2019) How Does Consumers' Omnichannel Shopping Behaviour Translate into Travel and Transport Impacts? Case-Study of a Footwear Retailer in Belgium. Sustainability, 11(9), 2534. https://doi.org/10.3390/su11092534

Chiu, H-C., Hsieh, Y-C., Roan, J., Tseng, K-J. and Hsieh, J-K. (2011) The challenge for multichannel services: Cross-channel free-riding behavior. Electronic Commerce Research and Applications, 10(2), 268-277. https://doi.org/10.1016/j.elerap.2010.07.002

De Keyser, A., Schepers, J. and Konuş, U. (2015) Multichannel customer segmentation: Does the after-sales channel matter? A replication and extension. International Journal of Research in Marketing, 32(4), 453-456. https://doi.org/10.1016/j.ijresmar.2015.09.005

Elogia (2018) Estudio Anual de Redes Sociales IAB 2018. Retrieved from https://www.reasonwhy.es/sites/default/files/estudio-redes-sociales-2018_iab.pdf

Eurostat (2020) E-commerce statistics for individuals. Retrieved from https://ec.europa.eu/eurostat/statistics-explained/index.php/Ecommerce_statistics_for_individuals

Frambach, R.T., Roest, H.C.A. and Krishnan, T.V. (2007) The impact of consumer internet experience on channel preference and usage intentions across the different stages of the buying process, Journal of Interactive Marketing, 21(2), 26-41 https://doi.org/10.1002/dir.20079

Frasquet, M., Mollá, A. and Ruiz, E. (2015) Identifying patterns in channel usage across the search, purchase and post-sales stages of shopping, Electronic Commerce Research and Applications, 14(6), 654-665. https://doi.org/10.1016/j.elerap.2015.10.002

Gensler, S., Verhoef, P.C. and Böhm, M. (2012) Understanding consumers' multichannel choices across the different stages of the buying process, Marketing Letters, 23(4), 9871003. https://doi.org/10.1007/s11002-012-9199-9

INE (2018) Encuesta Continua de Hogares (ECH). Retrieved November 30, 2018, from http://www.ine.es/dynt3/inebase/index.htm?type=pcaxisandpath=/t20/p274/serie/prov/p05a ndfile $=$ pcaxisandL $=0$ anddh $=0$ andcapse $=0 \% 0 \mathrm{~A}$ 
Kemperman, A.D., van Delft, L. and Borgers, A.W. (2015) Omni channel fashion shopping. In: Pantano, E. (Ed.): Successful technological integration for competitive advantage in retail settings. Hershey: IGI Global, 144-167. https://doi.org/10.4018/978-1-4666-8297-9.ch007

Kim, J. J., Song, H., Choi, J., Kim, Y. and Hong, J. (2019). Channel stickiness in the shopping journey for electronics: Evidence from China and South Korea. Journal of Business Research. In press. https://doi.org/10.1016/j.jbusres.2019.11.015

Lantz, B. and Hjort, K. (2013) Real e-customer behavioural responses to free delivery and free returns, Electronic Commerce Research, 13(2), 183-198. https://doi.org/10.1007/s10660013-9125-0

Levy, M., Weitz, B.A. and Beitelspacher, L.S. (2012) Retailing Management, Eighth Ed. McGraw-Hill/Irwin.

Liao, C., Palvia, P. and Lin, H.N (2010) Stage antecedents of consumer online buying behavior, Electronic Markets, 20(1), 53-65. https://doi.org/10.1007/s12525-010-0030-2

Miquel-Romero, M. J., Frasquet, M. and Molla-Descals, A. (2020) The role of the store in managing postpurchase complaints for omnichannel shoppers. Journal of Business Research, 109, 288-296. https://doi.org/10.1016/j.jbusres.2019.09.057

Modaes.es (2018) Informe de la moda online en España. Retrieved from https://www.modaes.es/files/000_2016/0001 publicaciones/pdfs/informe_ecommerce_2018 .pdf

Montoya-Weiss, M.M., Voss, G.B. and Grewal, D. (2003) Determinants of Online Channel Use and Overall Satisfaction with a Relational, Multichannel Service Provider, Journal of the Academy of Marketing Science, 31(4), 448-458. https://doi.org/10.1177/0092070303254408

Słowikowska, I. (2019) Millennials' Perspective on Multiple Distribution Channels. Annales Universitatis Mariae Curie-Skłodowska. Sectio H. Oeconomia, 53(1), 69-76. https://doi.org/ 10.17951/h.2019.53.1.69-76

Urueña, A., Prieto, E., Ballestero, M.P., Castro, R., Cadenas, S. and Seco, J.A. (2018) Estudio sobre comercio electrónico B2C $2017 . \quad$ Retrieved from https://www.ontsi.red.es/ontsi/es/estudios-informes/192

Verhoef, P.C., Kannan, P.K. and Inman, J.J. (2015) From Multi-Channel Retailing to OmniChannel Retailing, Journal of Retailing, 91(2), 174-181. https://doi.org/10.1016/j.jretai.2015.02.005

Verhoef, P.C., Neslin, S.A. and Vroomen, B. (2007) Multichannel customer management: Understanding the research-shopper phenomenon, International Journal of Research in Marketing, 24(2), 129-148. https://doi.org/10.1016/j.ijresmar.2006.11.002

Voorveld, H. A. M., Smit, E. G., Neijens, P. C. and Bronner, A. E. (2016). Consumers' CrossChannel Use in Online and Offline Purchases: An Analysis of Cross-Media and CrossChannel Behaviors between Products. Journal of Advertising Research, 56(4), 385-400. https://doi.org/10.2501/jar-2016-044

Yang, Y., Gong, Y., Land. L. P. W. and Chesney, T. (2020) Understanding the effects of physical experience and information integration on consumer use of online to offline commerce. International Journal of Information Management, 51, 102046. https://doi.org/10.1016/j.ijinfomgt.2019.102046

Zhai, Q., Cao, X., Mokhtarian, P.L. and Zhen, F. (2017) The interactions between e-shopping and store shopping in the shopping process for search goods and experience goods, Transportation, 44(5), 885-904. https://doi.org/10.1007/s11116-016-9683-9 